Оригинальная статья/Original article

УДК 658.14/.17

DOI: http://doi.org/10.20914/2310-1202-2018-3-494-499

Корпоративное финансирование как особый процесс. Роль микрокредитования в его организации

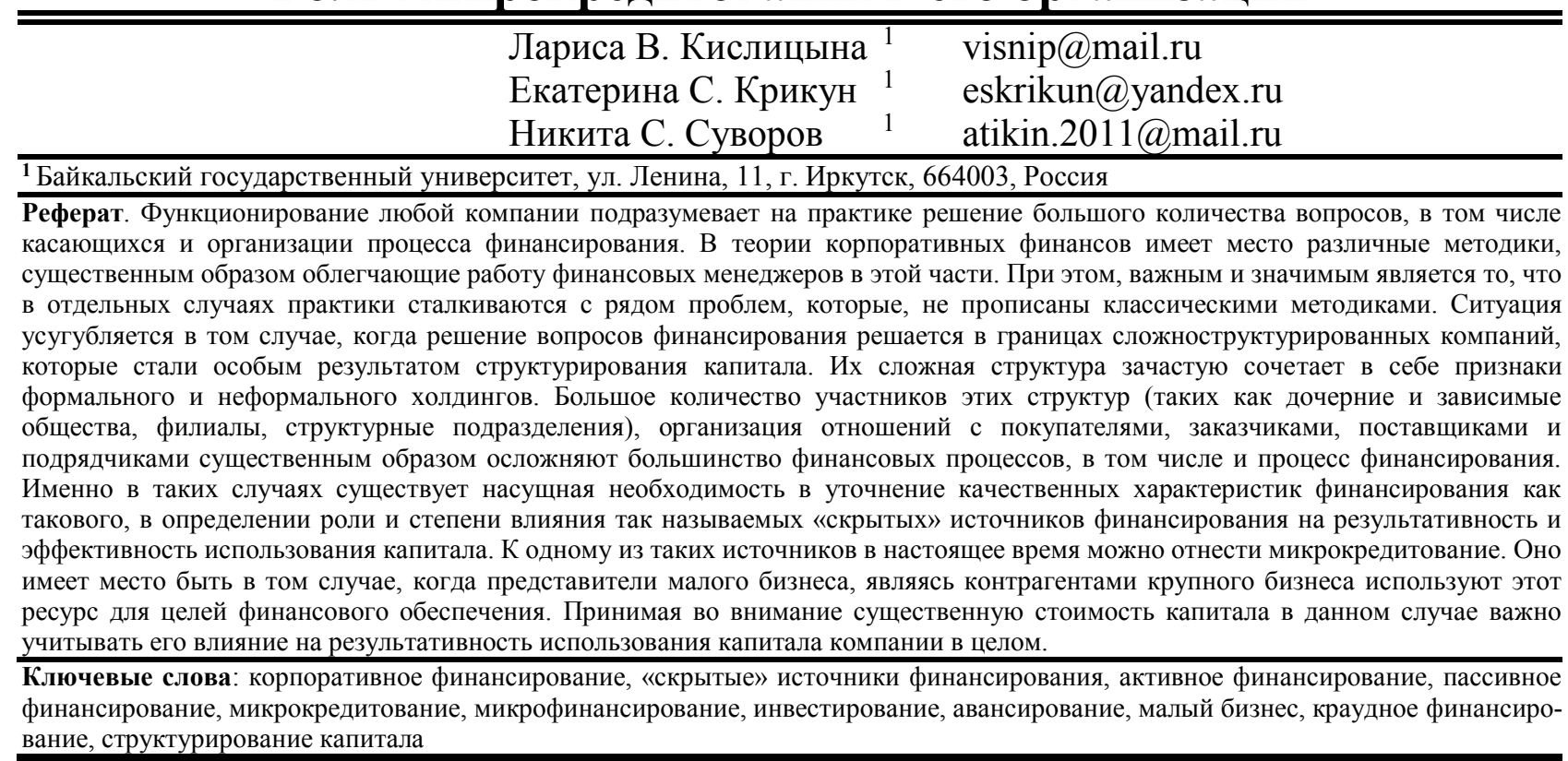

\title{
Corporate financing as a special process. The role of microcredit in it is organization
}

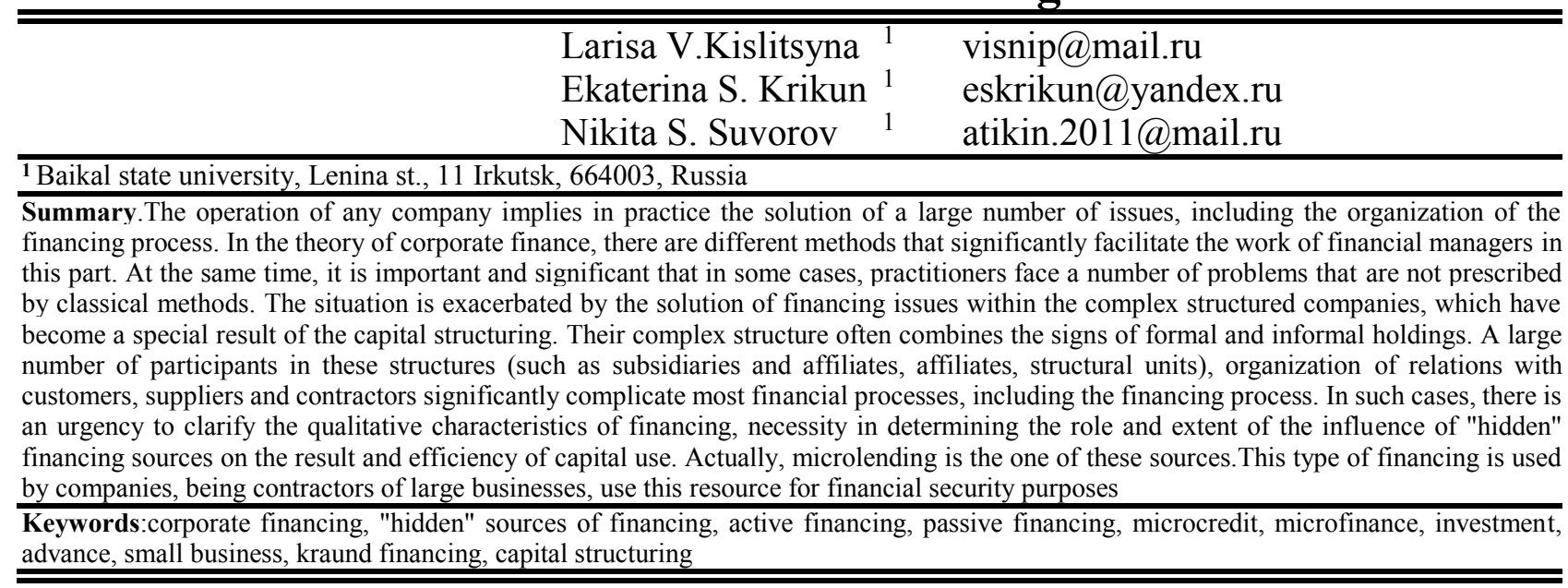

\section{Введение}

Как правило, характеризуя финансирование компании или корпоративное финансирование, внимание авторов сосредоточено либо на источниках финансирования, либо на направлениях использования капитала.

При этом не всегда целесообразно разделять такие две составляющие, как финансовое обеспечение и направление источников финансовых

\section{Для цитирования}

Кислицына Л.В., Крикун Е.С., Суворов Н.С. Корпоративное финансирование как особый процесс. Роль микрокредитования в его организации // Вестник ВГУИТ. 2018. Т. 80. № 3. С. 494-499. doi:10.20914/2310-1202-2018-3-494-499 ресурсов. Более того, отдельного внимания заслуживает процесс трансформации процесса финансирования, продиктованный различными причинами, в числе которых наиболее существенное значение имеют: реализация активнопассивного финансирования и использование так называемого «скрытого» финансирования (первоисточником которого выступает микрокредитование).

\section{For citation}

Kislitsyna L.V., Krikun E.S., Suvorov N.S. Corporate financing as a special process. The role of microcredit in it is organization. Vestnik VGUIT [Proceedings of VSUET]. 2018. vol. 80. no. 3. pp. 494-499. (in Russian). doi:10.20914/2310-1202-2018-3-494-499 
Цель работы - выявление особенностей содержания процесса корпоративного финансирования в современных условиях и определение роли микрокредитования как первоисточника «скрытого» финансирования в его организации.

Для достижения цели были поставлены следующие задачи: рассмотреть корпоративное финансирование как особый процесс, охарактеризовать направление трансформации финансирования в части реализации активно-пассивного финансирования, определить роль микрокредитования в организации процесса корпоративного финансирования.

Теоретико-методической основой исследования являлись работы отечественных и зарубежных авторов, чьи интересы касаются вопросов корпоративного финансирования, финансирования малого бизнеса, проблематики микрокредитования. Отдельные выводы в исследовании были сформулированы на базе научных трудов отечественных экономистов: Суходолова А.П., Жигас М.Г., Орловой Е.Н., Калачевой О.С., Киселева Д.А., Криворучко С.В. и др. Для настоящей работы особый интерес представляли научные труды зарубежных исследователей, которые внесли весомый вклад в разработку теоретических основ корпоративного финансирования, в числе которых: Коласс Б., Уолш К., Хикс Дж. Р.

Научная новизна состоит в развитии теоретических представлений о корпоративном финансировании как особом двуедином процессе и выявлении роли микрокредитования как первоисточника «скрытого» финансирования в его организации.

Теоретическая значимость заключается в уточнении содержания понятия «корпоративное финансирование» в части реализации его в активно-пассивной форме.

Практическая значимость работы заключается в возможности использования полученных выводов при принятии решений в части организации процесса финансирования.

\section{Материалы и методы}

Использовали системный подход при анализе корпоративного финансирования как особого процесса. Рассматривали роль микрокредитования путем выделения особенностей применения этого источника финансирования. Эмпирическими методами исследования являлись: наблюдение, сравнение, синтез теоретического и практического материала, выборка и обобщение.

Традиционно процесс управления капиталом компании ориентирован на максимизацию стоимости бизнеса, которая является одним из ключевых показателей результативности [1-3]. При этом для достижения определенного уровня результативности управления компанией важно и значимо качественным образом организовать процесс финансирования как таковой. Если же сделать акцент либо на финансовом обеспечении, либо на направлениях использования уже сформированного капитала, то существует вероятность конфликта интересов заинтересованных сторон и нарушения финансового равновесия. А следовательно, характеризуя корпоративное финансирование как особый процесс и обеспечивая его организацию в практической деятельности, необходимо одновременно уделять внимание обеспечению финансовыми ресурсами и направлениям их использования. На практике организация финансирования представляет собой процесс принятия решений в части выбора форм, способов, источников капитала и решений об определении направлений использования привлеченных ресурсов. Выбор касается трех основных крупных направлений: вложение (инвестирование), авансирование и расходование. При этом реализация любого из названных направлений предполагает выбор источников финансового обеспечения, содержания обязательств и генерирования тех или иных результатов.

Для полноты характеристики финансирования компании в части финансового обеспечения используют различные классификации. Любая из известных классификаций дает возможность сосредоточиться в каждом конкретном случае на качественно разнородных характеристиках корпоративного финансирования.

Можно анализировать финансирование с учетом связи источников финансового обеспечения с хозяйственными операциями или связи с рынками и разделять такие составляющие финансового обеспечения как внутреннее и внешнее финансирование. При этом все операции, реализуемые в процессе внешнего финансирования, предполагают непосредственную связь с рынками капитала. А операции в части внутреннего финансирования есть результат в ходе платежных отношений между компаниями и рынками нефинансовой сферы.

Интерес представляет классификация внешнего финансирования в зависимости от субъектов, предоставляющих капитал в распоряжение компании. Здесь возможно различать финансирование за счет: капитала постоянных собственников, новых собственников, кредиторов, а также за счет заимодателей с одновременным сочетанием прав собственников и кредиторов.

Использование иного классификационного подхода, в основе которого заложены источники капитала, позволяет качественно охарактеризовать внутреннее финансирование. Именно капитализация прибыли либо высвобожденный 
из оборота ранее авансированный капитал подразумеваются под источниками финансирования в данном случае. Высвобождение капитала может осуществляться такими способами, как: реализация непрофильных активов, обеспечение входящего денежного потока в виде амортизации, доходов от реализации непрофильных активов и прибыли, сформированной за счет ускорения оборачиваемости имеющегося капитала. Используя внутреннее финансирование, компания создает для себя возможность обеспечить активное финансирование, которое отличается качественной особенностью. Последняя проявляется в том, что высвобождение капитала в данном случае определяется как результат совокупности операций, сопровождающих высвобождение капитала компании ранее был вложенного (авансированного) в ее активы [4].

Практическим примером высвобождения капитала могут являться финансовые потоки в виде выручки, генерируемые в результате повышения скорости оборачиваемости оборотного капитала компании. Обособление в составе выручки амортизации как составного элемента cash flow позволяет качественно уточнить анализ указанного направления финансирования.

Реализация активного финансирования посредством высвобождения капитала позволяет получить для компании различные экономические выгоды: существенное сокращение потребности во внешних источниках финансирования, в накоплении собственного капитала, а также повышение отдачи капитала в целом.

Активное финансирование в форме ускорения оборачиваемости капитала сокращает потребность во внешних источниках финансирования, однако обеспечивается исключительно высоким качеством управленческих решений финансовых менеджеров.

Внешнее финансирование, в свою очередь, является составляющим элементом пассивного финансирования. Последнее есть результат совокупности операций, посредством которых капитал может быть мобилизован в распоряжение компании от различных кредиторов. Использование этого финансирования особым образом влияет на изменение содержания и статей пассива баланса. Качественно уточнить характеристику финансирования в данном случае возможно, разграничив его источники на собственную, заемную и привлеченную составляющие.

Собственный капитал как одна из составляющих финансового обеспечения предполагает чаще всего практически неограниченный срок предоставления с сочетанием непосредственного участия его собственников в управлении компанией. Отличительной особенностью заемного капитала является то, что он предоставляется кредиторами с обязательным выполнением условий возвратности, срочности и платности.

Привлеченный капитал в компании чаще всего представлен в форме кредиторской задолженности, формирующейся при организации отношений с различными контрагентами в виде: предоплаты со стороны покупателей, передачи финансовых ресурсов в рамках отношений с материнской компанией, пополнения оборотного капитала за счет финансовых потоков в результате отношений с поставщиками и временного удержания инкассированной выручки в части, предназначенной для расчетов с контрагентами.

В каждом конкретном случае обращает на себя внимание процесс трансформации процесса финансирования как такового. В настоящее время особый интерес представляет такая часть кредиторской задолженности, как задолженность перед подрядчиками. В том случае когда отношения с этими контрагентами были оформлены в результате процесса структурирования компаний посредством структурирования их капитала, в ходе которого, как правило, выполнение многих видов работ было передано сторонним организациям с целью оптимизации налоговой нагрузки и обеспечения сбалансированности денежных потоков при одновременном предоставлении подрядчикам, например, на условиях аренды имущества компании. Другими словами, в данном случае имеет место сочетание форм активного и пассивного финансирования.

\section{Результаты и обсуждение}

Учитывая особенности формирования источника финансирования в виде кредиторской задолженности, в данном случае можно такую форму финансового обеспечения квалифицировать как активно-пассивное финансирование.

Для оценки результативности такого процесса финансирования необходимо учитывать стоимость капитала фирмы-подрядчика. Особый интерес здесь представляют контрагенты, являющиеся представителями малого бизнеса. Теоретически капитал малого бизнеса в качестве источников ресурсов может использовать собственные, заемные и привлеченные средства. В последнее время повышен интерес к малому и среднему бизнесу представителей российского рынка лизинговых услуг. Не случайно в работе Суходолова А.П. и Кульдюковой И.В. именно этот сегмент отмечен в качестве перспективного [5]. Также активно обсуждаются возможности использования краудного финансирования как альтернативного источника финансового обеспечения предприятий малого бизнеса [6-9]. Инновационную деятельность малого бизнеса традиционно связывают с венчурным финансированием [10]. 
Практический интерес для целей настоящей работы представляет качественное наполнение отдельных составляющих.

Возможность привлечения заемных средств ассоциируется, как правило, с банковским сектором. К слову сказать, в России в настоящее время именно он и является доминирующим поставщиком финансовых услуг. Однако в последние годы все большую популярность приобретает микрофинансирование [11].

На сегодняшний момент термин «микрофинансирование» трактуется не всегда однозначно [12]. Чаще всего его рассматривают с позиции «процесса предоставления различных финансовых услуг (кредиты, сбережения, денежные переводы, страхование) клиентам преимущественно с низкими доходами». В этом случае понятие «микрофинансирование» фактически отождествляется с «микрокредитованием», то есть оказанием услуг по предоставлению небольших по сумме и недостаточно обеспеченных краткосрочных заемных финансовых ресурсов. Такая трактовка аргументирует и мнение многих авторов о том, что основное внимание к микрофинансированию привлечено как к инновационному инструменту развития кредитной системы.

Микрофинансирование ассоциируется с личными финансами (финансами домохозяйств) и действительно очень востребовано в этой сфере в качестве источника финансирования. Микрофинансирование субъектов малого предпринимательства также может осуществляться через компании-МФО. По мнению многих авторов, создание именно эффективной системы кредитования, прежде всего для дополнительного стимулирования производства и услуг, а также оказания помощи начинающим предпринимателям в приобретении опыта получения прибыли и накопления первоначального капитала [13]. Но по данным официальной статистики ЦБ РФ доля микрокредитов для малого бизнеса незначительна и составляет в среднем $6-7 \%$ от числа общей суммы задолженности.

В контексте настоящей работы важно заметить, что как источник финансовых ресурсов малого бизнеса может быть перенаправлено микрофинансирование из сферы личных финансов. При этом анализу и оценке такое перераспределение потоков практически не поддается, справедливо отмечено, что зачастую домохозяйства относятся к так называемым субъектам ненаблюдаемой экономики [14], что позволяет характеризовать этот источник как «скрытый». И если по разным оценкам доля физических лиц в числе кредиторов МФО занимает до $85 \%$, то можно с уверенностью утверждать, что в их числе значительная доля заимствований, основной целью которых является направление «личных» финансов с рынка микрокредитования на предпринимательскую деятельность, например, на цели финансирования кассовых разрывов при ведении бизнеса. Проблема сбалансированности денежных потоков в сфере представителей малого бизнеса очень актуальна. Она является текущей задачей и для фирм-подрядчиков, деятельность которых оформлена договорными отношениями с крупным бизнесом. Так, например, расчеты за выполненные работы осуществляются с существенным временным лагом после подписания актов выполненных работ и проверки качества этих работ. Причина здесь зачастую техническая, связана с особенностями исполнения бюджетов сложно структурированной компании-заказчика, но для представителя малого бизнеса она может стать существенной. И результатом процесса организации финансирования фирмыподрядчика является вынужденная мера: привлечение ресурсов на единственно доступном для них рынке, а следовательно, и более дорогостоящем, а именно на рынке микрокредитования. Проблематика заключается в низком уровне финансового потенциала представителей микробизнеса. А его тесная связь с домохозяйством только усугубляет проблему [15-20].

В итоге высокая (в отдельных случаях до $10 \%$ в день) стоимость ресурсов компанииподрядчика прямо или косвенно влияет на результативность процесса финансирования и компании-заказчика. Прямое влияние проявляется в том, что подрядчик, учитывая повышенную цену капитала, вынужден повышать стоимость работ. Косвенное же влияние имеет место в том случае, когда представители крупного бизнеса (заказчика в данном случае) фиксируют стоимость услуг подрядчика в рамках договорных отношений. Последний, в свою очередь, компенсируя для себя потерю рентабельности за счет повышенной стоимости используемого капитала, вынужденно снижает финансирование текущих расходов, что приводит к снижению качества ресурсов (трудовых, материальных и других) и снижению качества работ.

\section{Заключение}

Хотелось бы отметить, что трансформация процесса корпоративного финансирования продиктована сегодняшними реалиями и скорее всего найдет свое продолжение в виде различных схем финансирования в дальнейшем. Отдельно стоит подчеркнуть, что сформулированные в настоящей работе выводы о трансформации процесса корпоративного финансирования могут стать основой для дальнейших научных исследований. 


\section{ЛИТЕРАТУРА}

1. Коласс Б. Управление финансовой деятельностью предприятия. Проблемы, концепции и методы: учеб. пособие: пер. с франц. М.: Финансы, ЮНИТИ, 1997. 576 с.

2. Хикс Дж.Р. Стоимость и капитал: пер. с англ. М.: Прогресс, 1993.

3. Уолш К. Ключевые показатели менеджмента. Как анализировать, сравнивать и контролировать данные, определяющие стоимость компании: пер. с англ. М.: Дело, 2000. 360 с.

4. Винокурова В.П., Кислицына Л.В. Структурирование предприятий как предпосылка для изменения направленности их финансирования // Известия ИГЭА. 2010. № 1 (69). С. 18-23.

5. Суходолов А.П., Кульдюкова И.В. Особенности финансирования субъектов малого бизнеса с применением лизинговой схемы // Известия Иркутской государственной экономической академии. 2011. № 3 (77). С. 22-25.

6. Киселев Д.А., Фоканова Е.А. Краудинвестинг как источник финансирования малого бизнеса в условиях кризиса // Science time. 2015. № 11 (23). С. 246-250.

7. Василенко Т.А. Особенности развития краудлендинга в России // Символ науки. 2015. № 5. C. $90-94$.

8. Хау Дж. Краудсорсинг. Коллективный разум как инструмент развития бизнеса. Москва: Альбина паблишер, 2012. 288 с.

9. Green Ch.H.. Banker's guide to New Small Business Finance. N.J.: Wiley, 2014.

10. Калачева О.С. Венчурное финансирование и инновационная активность малого предпринимательства // Бизнес. Образование. Право. Вестник Волгоградского института бизнеса. 2010. № 1. С. 155-159.

11. Жигас М.Г., Петрова И.А. Тенденции микрофинансирования в России // Baikal research journal. 2018. T. 9, № 2. doi: 10.17150/2411-6262.2018.9(2).1

12. Абелев О. Институт микрофинансирования в России: перспективы развития бизнеса // Рынок ценных бумаг. 2013. № 1. С. 32-35.

13. Криворучко С.В., Абрамова М.А. Микрофинансирование в России. М.: КНОРУС: ЦИПСиР, 2013. 168 с.

14. Орлова Е.Н. Домохозяйства как субъекты ненаблюдаемой экономики // Baikal research journal. 2013. № 1. С. 22-25.

15. Кислицына Л.В., Унтанов А.Б. Теоретические аспекты финансов домашних хозяйств // Baikal research journal. 2015. Т. 6. № 2. doi: 10.17150/20720904.2015.6(2).7 URL: http://eizvestia.isea.ru/reader/article.aspx?id=20019

16. Freund S., Latif S., Phan H. V. Executive compensation and corporate financing policies: Evidence from CEO inside debt // Journal of corporate finance. 2018. .V 50. P. 484-504.

17. Nguyen T., Nguyen H. G., Yin X. Corporate governance and corporate financing and investment during the 2007-2008 financial crisis // Financial management. 2015. V. 44. №. 1. P. 115-146.

18. Ayturk Y. The effects of government borrowing on corporate financing: Evidence from Europe // Finance research letters. 2017. V. 20. P. 96-103.
19. Drover W., Busenitz L., Matusik S., Townsend D. et al. A review and road map of entrepreneurial equity financing research: venture capital, corporate venture capital, angel investment, crowdfunding, and accelerators // Journal of management. 2017. V. 43. №. 6. P. 1820-1853.

20. Lennox C., Wang Z.T., Wu X. Earnings management, audit adjustments, and the financing of corporate acquisitions: Evidence from China // Journal of accounting and economics. 2018. V. 65. №. 1. P. 21-40.

\section{REFERENCES}

1. Colasse B. Upravlenie finansovoj deyatel'nost'yu predpriyatiya. Problemy, koncepcii i metody [Financial management of the company. Problems, concepts and methods]. Moscow, Finance, Unity, 1997. 576 p. (in Russian).

2. Hicks J.R. Stoimost' i kapital [Value and capital]. Moscow, Progress, 1993. (in Russian).

3. Walsh K. Klyuchevye pokazateli menedzhmenta. Kak analizirovat', sravnivat' i kontrolirovat' dannye, opredelyayushchie stoimost' kompanii [Key management ratios. How to analyze, compare and control the figures that drive company value]. Moscow, Delo, 2000. 360 p. (in Russian).

4. Vinokurova V.P., Kislitsyna L.V. Enterprises structuring as a prerequisite for their financing modification. Izvestiya Irkutskoi gosudarstvennoi ekonomicheskoi akademii [News of the Irkutsk State Economic Academy]. 2010. no 1 (69). pp. 18-23.

5. Sukhodolov A.P., Kuldyukova I.V. Peculiarities of financing small business using leasing scheme. Izvestiya Irkutskoi gosudarstvennoi ekonomicheskoi akademii [News of the Irkutsk State Economic Academy]. 2011. no. 3 (77). pp. 22-25. (in Russian).

6. Kiselev D.A., Fokanova E.A. Crowd-investing as a source of funding small businesses in terms of crisis. Science time. 2015. no. 11 (23). pp. 246-250. (in Russian).

7. Vasilenko T.A. The main features of Crowdlending development in Russia. Simvol nauki [Symbol of science]. 2015. no. 5. pp. 90-94. (in Russian).

8. Howe J. Kraudsorsing. Kollektivnyj razum kak instrument razvitiya biznesa [Kraudsorsing. Crowdsourcing. Why the power of the crowd is driving the future of business]. Moscow, Albina publisher, 2012. 288 p. (in Russian).

9. Green Ch.H. Banker's guide to New Small Business Finance. N.J., Wiley, 2014.

10. Kalacheva O.S. Venture financing and innovative activity of small business. Biznes. Obrazovanie. Pravo. Vestnik Volgogradskogo instituta biznesa. [Business. Education. Right. Bulletin of volgograd business institute]. 2010. no. 1. pp. 155-159. (in Russian).

11. Zhigas M.G., Petrova I.A. Trends of Microfinancing in Russia. Baikal research journal. 2018. vol. 9. no. 2. doi: 10.17150/2411-6262.2018.9(2).1 (in Russian).

12. Abelev $\mathrm{O}$. The institute of micro-financing in Russia: prospects of business development. Rynok tsennykh bumag [Securities market]. 2013. no. 1. pp. 32-35. (in Russian).

13. Krivoruchko S.V., Abramova M.A. Mikrofinansirovanie v Rossii [Micro-financing in Russia]. Moscow, KNORUS, CIPSiR, 2013. 168 p. (in Russian).

14. Orlova E.N. Households as entities of nonobserved economy. Baikal research journal. 2018. no 1. pp. 22-25. (in Russian). 
15. Kislitsyna L.V., Untanov A.B. Theoretical aspects of household finance. Baikal research journal. 2015. vol. 6. no. 2. Available at: http://eizvestia.isea.ru/reader/article.aspx?id=20019 doi: 10.17150/2072-0904.2015.6(2).7 (in Russian)

16. Freund S., Latif S., Phan H.V. Executive compensation and corporate financing policies: Evidence from CEO inside debt. Journal of corporate finance. 2018. vol. 50. pp.484-504.

17. Nguyen T., Nguyen H.G., Yin X. Corporate governance and corporate financing and investment during the 2007-2008 financial crisis. Financial management. 2015. vol. 44. no. 1. pp. 115-146.

\section{СВЕДЕНИЯ ОБ АВТОРАХ}

Лариса В. Кислицына к.э.н., доцент, кафедра «Финансы и финансовые институты», Байкальский государственный университет, ул. Ленина, 11, г. Иркутск, 664003, Россия, visnip@mail.ru

Екатерина С. Крикун ст.преподаватель, кафедра «Финансы и финансовые институты», Байкальский государственный университет, ул. Ленина, 11, г. Иркутск, 664003, Россия, eskrikun@yandex.ru

Никита С. Суворов аспирант, кафедра «Финансы и финансовые институты», Байкальский государственный университет, ул. Ленина, 11, г. Иркутск, 664003, Россия, atikin.2011@mail.ru

\section{КРИТЕРИЙ АВТОРСТВА}

Лариса В. Кислицына написала рукопись, корректировала её до подачи в редакцию и несёт ответственность за плагиат Екатерина С. Крикун консультация в ходе исследования Никита С. Суворов обзор литературных источников по исследуемой проблеме

\section{КОНФЛИКТ ИНТЕРЕСОВ}

Авторы заявляют об отсутствии конфликта интересов.

ПОСТУПИЛА 03.05.2018

ПРИНЯТА В ПЕЧАТЬ 13.07.2018
18. Ayturk Y. The effects of government borrowing on corporate financing: Evidence from Europe. Finance research letters. 2017. vol. 20. pp. 96-103.

19. Drover W., Busenitz L., Matusik S., Townsend D. et al. A review and road map of entrepreneurial equity financing research: venture capital, corporate venture capital, angel investment, crowdfunding, and accelerators. Journal of management. 2017. vol. 43. no. 6. pp. 1820-1853.

20. Lennox C., Wang Z.T., Wu X. Earnings management, audit adjustments, and the financing of corporate acquisitions: Evidence from China. Journal of accounting and economics. 2018. vol. 65. no. 1. pp. 21-40.

\section{INFORMATION ABOUT AUTHORS}

Larisa V.Kislitsyna Cand. Sci. (Econ.), associate professor, finance and financial institutions department, Baikal state university, Lenina st., 11, Irkutsk, 664003, Russia, visnip@mail.ru

Ekaterina S. Krikun senior lecturer, finance and financial institutions department, Baikal state university, Lenina st., 11, Irkutsk, 664003, Russia , eskrikun@yandex.ru

Nikita S. Suvorov graduate, ,finance and financial institutions department, Baikal state university, Lenina st., 11, Irkutsk, 664003, Russia, atikin.2011@mail.ru

\section{CONTRIBUTION}

Larisa V.Kislitsyna wrote the manuscript, correct it before filing in editing and is responsible for plagiarism

Ekaterina S. Krikun consultation during the study

Nikita S. Suvorov review of the literature on an investigated problem

\section{CONFLICT OF INTEREST}

The authors declare no conflict of interest.

RECEIVED 5.3.2018

ACCEPTED 7.13.2018 